\title{
Smart Net Energy Metering System
}

\section{Rahman IU*}

Electrical Engineering Department, lqra National University, Peshawar, Pakistan

\begin{abstract}
With the proliferation of distributed generation technologies and renewable energy electric power system is becoming more complex. In traditional grid system and current energy metering infrastructure line losses are growing day by day. This project will enable smart net energy metering by using GSM technology, user will not only able to view real time usage of energy but also will be able to sell excessive energy to utility which is produced in the vicinity of user.

Either Renewable or nonrenewable energy resources can be utilized and controlled remotely through mobile application, the energy sold out to utility will be deducted from energy consumed from utility which enables dual way smart net energy metering system. Net metering makes residential solar energy system ownership even more attractive and affordable for many families. It can save homeowners hundreds more rupees per year on their utility bills, and it makes the process of accounting for the energy flowing to and from the utility simpler and easier to administer.
\end{abstract}

Keywords: Metering system; Smart metering system; GSM; Android application

\section{Introduction}

The use of renewable energy has greatly increased because of the growing demand of oil which has increased the prices of oil. We know most of the traditional grids does not uses renewable energy sources and hence their prices are very high. In this project you have your own renewable energy source in your home the electricity that your renewable system generates serves your home's energy needs and reduces your monthly electric bill. When your system generates more electricity than your home can use the surplus energy exports to electric grid which will also decrease your bill. The whole system will be accessed real time through GSM module which give you information of your system any time you need. This access is made easier through a android application which is installed in your mobile [1].

\section{Smart Metering}

Net metering makes residential solar energy system ownership even more attractive and affordable for many families. It can save homeowners hundreds more rupees per year on their utility bills, and it makes the process of accounting for the energy flowing to and from the utility simpler and easier to administer. If you have an electricity generation system that uses a renewable fuel source at your home or business and your system(s) produces more energy than you use, you can earn bill credits for excess power that flows from your system to electricity grid. This give-and-take is referred to as Net Energy Metering or NEM. In this project you are going to control this process through mobile switching portal $[2,3]$.

If you need energy when the sun isn't shining at all, that power is supplied from the utility grid. If your solar power system produces more electricity than you need, the extra electricity gets delivered back to the utility grid. If you live in a state with net metering, then you get credited for the electricity you deliver back to the grid at the same retail price that you pay for the electricity you take from the grid. And the energy you are giving to the grid is given to another home by the grid and hence helps in providing energy requirements.

"Net metering is an electricity policy for consumers who own renewable energy facilities (such as ... solar power) which allows them to use electricity whenever needed while contributing their production to the outside." In the Philippines, net-metering is the first policy mechanism of the Renewable Energy Act of 2008 which has been fully implemented. The picture below illustrates the flow of electricity from power generation via high voltage transmission and distribution utilities to the end-user who can now install a renewable energy facility and send not needed electricity back into the distribution grid and earn credit for this export [4].

\section{Metering System}

An electricity meter, electric meter, electrical meter, or energy meter is a device that measures the amount of electric energy consumed by a residence, a business, or an electrically powered device.

Electric utilities use electric meters installed at customers' premises to measure electric energy delivered to their customers for billing purposes. They are typically calibrated in billing units, the most common one being the kilowatt hour $[k W h]$. They are usually read once each billing period.

When energy savings during certain periods are desired, some meters may measure demand, the maximum use of power in some interval. "Time of day" metering allows electric rates to be changed during a day, to record usage during peak high-cost periods and offpeak, lower-cost, periods. Also, in some areas meters have relays for demand response load shedding during peak load periods [5].

CT $s$ are used in metering system to find the amount of current flowing through the specific wire and then the ampears calculated from that CTs is multiplied with the voltage in these lines which in turn gives us the power. The electricity is hence measured in $\mathrm{KW} / \mathrm{h}$.

*Corresponding author: Rahman IU, Electrical Engineering Department Iqra National University, Peshawar, Pakistan, Tel: 00923087776103; E-mail: Engr.ibad707@gmail.com

Received June 07, 2018; Accepted November 23, 2018; Published November 30, 2018

Citation: Rahman IU (2018) Smart Net Energy Metering System. J Electr Electron Syst 7: 285. doi: 10.4172/2332-0796.1000285

Copyright: (c) 2018 Rahman IU. This is an open-access article distributed under the terms of the Creative Commons Attribution License, which permits unrestricted use, distribution, and reproduction in any medium, provided the original author and source are credited. 


\section{Main Components of SNEMS}

\section{CTs}

CTs calculate the current passing through it and hence gives this signals to microcontroller for further workings.

\section{Relays}

There are two relays used in this meter one relay is used in choosing source either WAPDA or renewable energy source (Solar energy). The second relay is used in controlling of the energy going out of the home. It means it controls when to sale energy and when not to sale.

\section{LCD}

LCD is used to view the important information on its screen. It shows WAPDA consumed units, WAPDA sale units, Total bill (consumed-sale) and battery information accordingly.

\section{Microcontroller}

A "PIC16F877" is used here for the major operations to be performed.

\section{GSM Module}

GSM Module is used in this meter for real time access to the meter. It will send you the billing information when ever required by a person. Through this GSM module you can also control the relays and controls the whole meter anywhere in the world.

\section{Relay driver}

As we know the controller we are using in this meter does not have enough power to operate the relays so we have used a relay driver so that relays are given power and hence perform the required operation.

\section{Cristal oscillator}

Cristal oscillator generates a constant pulse which will help the relay driver to work.

\section{Circuit energizers}

For circuit energizing we have used a transistor which will give a constant 5V DC to the circuit to work properly [6].

\section{Hardware Overview}

Smart meters are a type of meters which are able to count the electrical energy moving in both directions. Suppose when you are getting energy from the grid the units are counted against you but in case of smart net energy metering when you are giving energy to the grid station there units are subtracted from the units counted against you and hence make energy counting in both ways that is why it is called smart meter because it has two way communication (Figures 1 and 2) [7].

- Two types of loads:

$\square$ Home load

$\square$ Sale load

- Two types of energy sources

$\checkmark$ Energy supply company

$\square$ Renewable energy source (Solar)

- Two CT (current transformer)

One to measure the amount of current used in home.

$\square$ One to measure the amount of current used by the load out of your home.

- Circuit energizer

$\square$ A voltage regulator 7805 has been used in the circuit to energize the whole circuit.

- GSM module is installed for two functions:

For real time access

For real time control

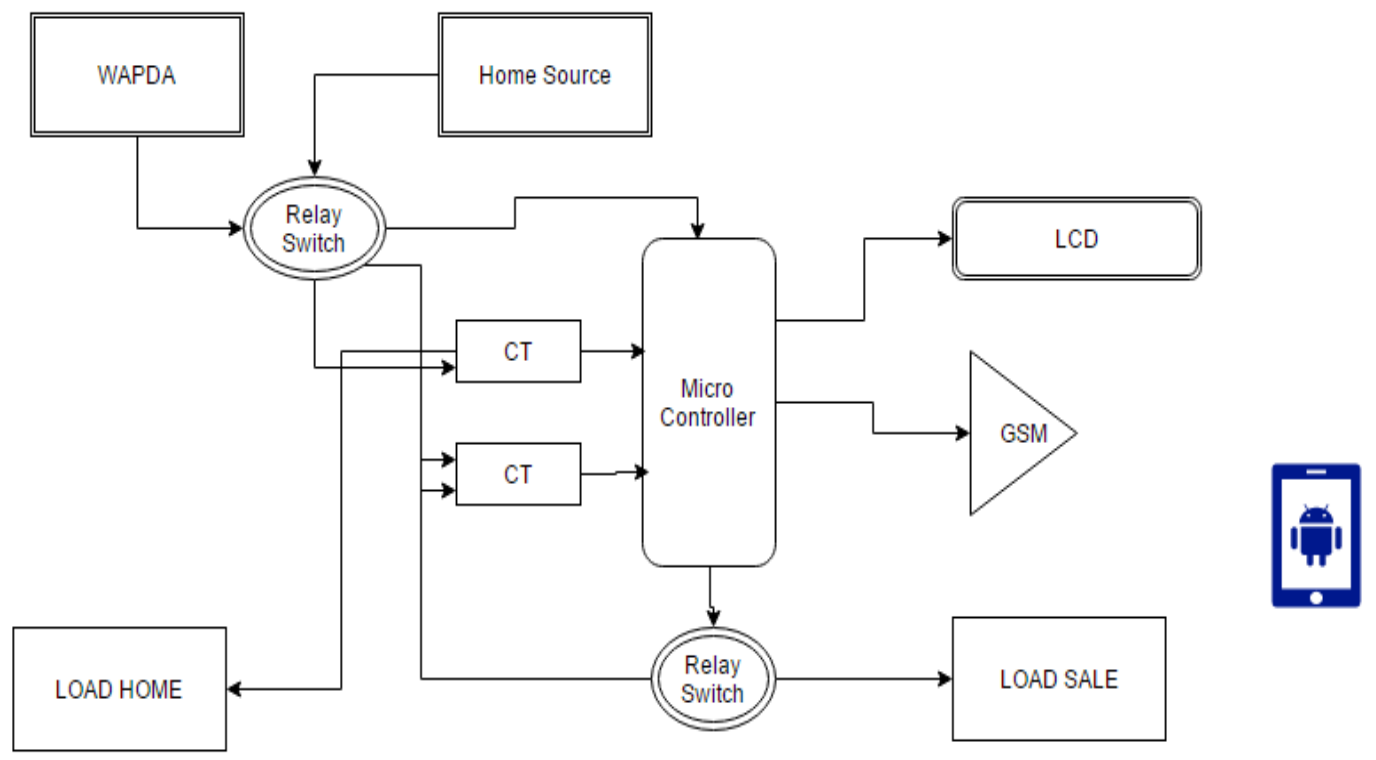

Figure 1: Block Diagram. 
- LCD screen is installed in the meter to show the detailed view of the different readings and battery status

- Micro controller is installed to govern all the process.

- Relays are installed to on and off the respective loads

- Relay driver is installed to give energy to the relays

- Crystal oscillator is for giving a constant pulse to the relay driver.

- Contrast controller is also present with the LCD screen to have the control of the LCD's contrast

- Pull up pull down capacitors are used with CT's to have a constant signal from the CT to microcontroller

- Other capacitors are used to stop noise.

\section{Working}

1. First check your distribution generation status.

2. If it has excessive energy then your need, you start selling through mobile application.

3. After some time again check your status.

4. If you don't have excess energy then stop sale.

5. Change the source to use the energy from the electric supply company (Figure 3).

\section{Mobile Application}

Mobile switching portal is a type of control of all smart net energy metering system. We can control all this either through GSM system which uses a mobile number to control the system by sending specific commands to that specific number. For example if we are not in home we can switch on or off all our loads and hence send our surplus energy to the grid to take the credit in reward (Figures 4 and 5).

Through this application you will be able to perform two functions.

\section{Real time access}

As discussed before we have installed GSM module in our SNEMS so whenever wherever we want to check our billing information we can check it by just pressing bill info. It will send us a message which will have detail of the bill Figure 6 .

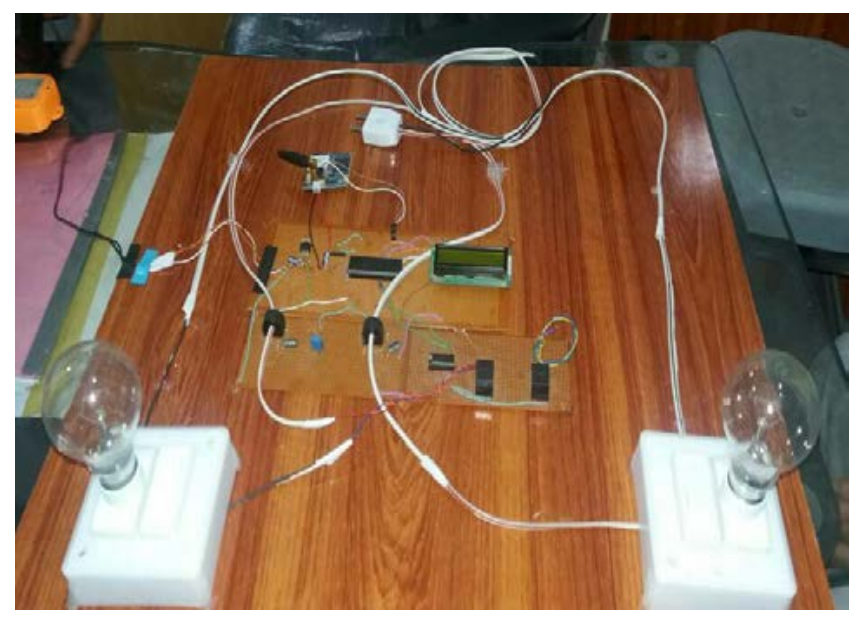

Figure 2: Smart Net Energy Meter.

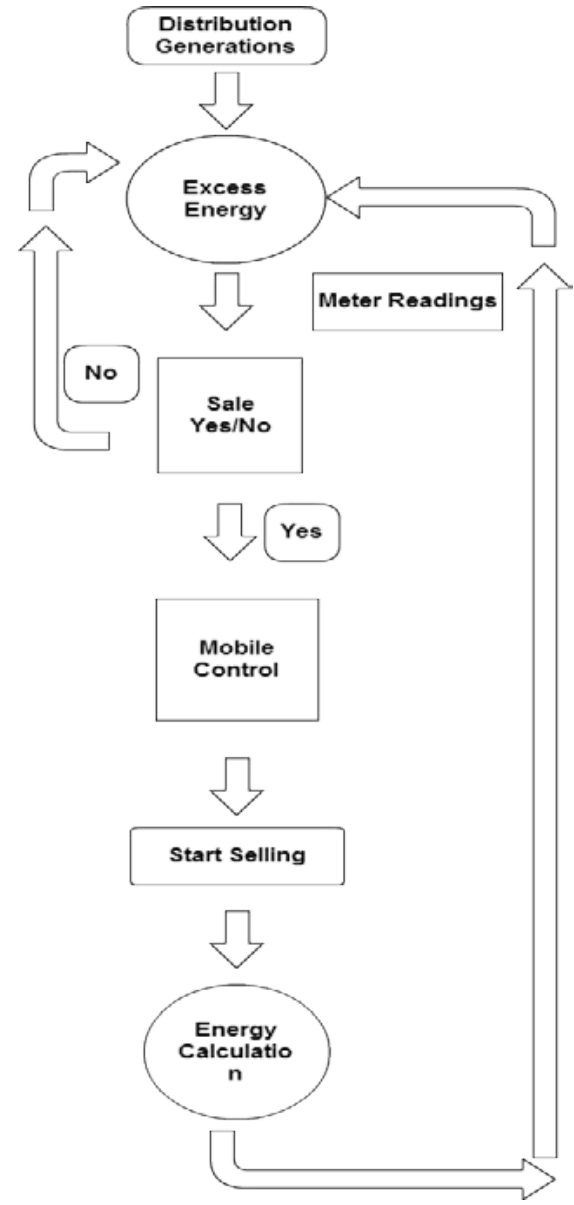

Figure 3: Flow Chart.

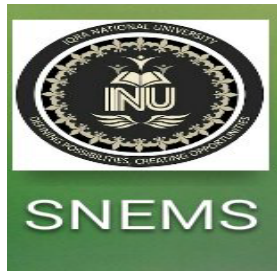

Figure 4: Monogram.

Here

Bat stands for Battery status

T.B stands for Total bill

W.S stands for WAPDA Sale the energy which we were having in excess and we sold it

W.C stands for WAPDA consumption the energy which we consumed from grid.

\section{Real time control}

Real time control means we can control our meter when we want to sale and when we want to use our own energy. 


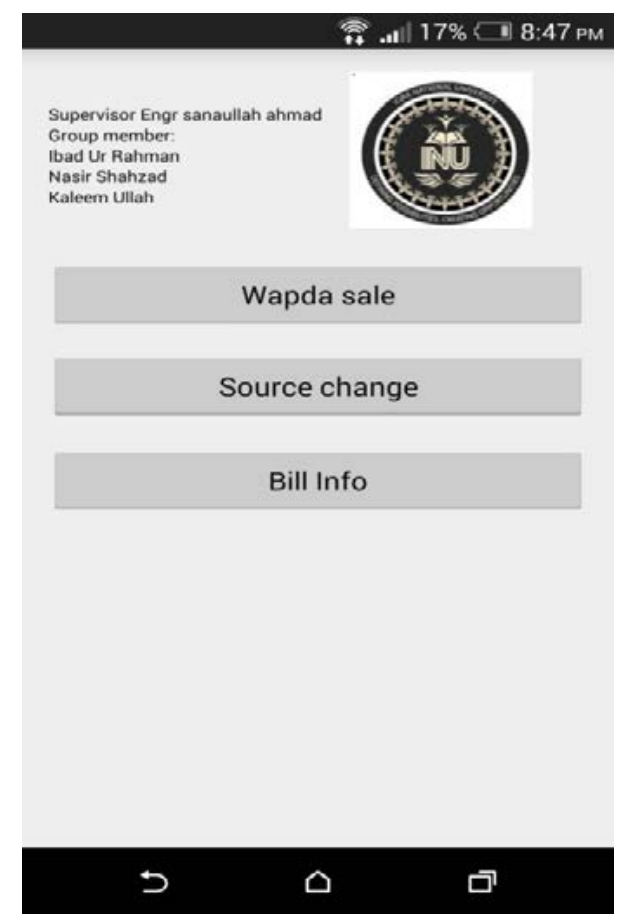

Figure 5: Andriod Application.

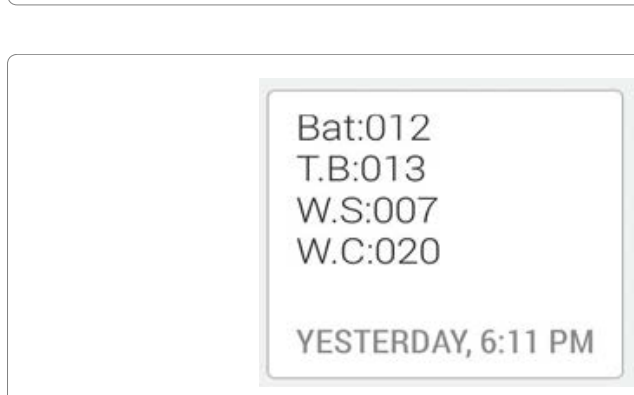

Figure 6: A Detailed Message.

We can control two things:

We can start and stop the excess energy we are selling.
And we can control which energy source we should use depending upon our requirement

Either our renewable energy source or Electric Supply Company.

\section{Conclusion}

Smart Net Energy Metering System is a project regarding the Metering system where we have renewable energy and we can use us it in very efficient way. The renewable energy is first used for your own energy consumption but if there is any extra energy left that energy is not wasted but it is used by sending it back to the grid. And in result you will get the credit for those units which you have sold to the grid.

This all system is accessed through a android application which is connected with the system through GSM which is accessed worldwide. So if you are any where you can check your energy bill and sell your extra renewable energy on grid and control it.

The android application designed for this system is very easy to use it has simple three buttons which are specified with their application and one can easily understand and control the whole system.

Real time access, high accuracy class and easy energy management through android application are some of it features which makes it far better than the energy meters used conventionally nowadays. Moreover if it is installed worldwide maximum amount of energy will be produced by the consumers them self and hence the energy demand can be completed easily through this system.

\section{References}

1. Arif A, Al-Hussain M, Al-Mutairi N, Al-Ammar E, Khan Y (2013) Experimental Study and Design of Smart Energy Meter for the Smart Grid. IRSEC.

2. Sarangle RG, Khot UP, Modi J (2014) Gsm Based Power Meter Reading and Control System. IJERA 1: 274-279.

3. Rashdi A, Malik R, Rashid S, Ajmal A, Sadiq S (2012) Remote Energy Monitoring, Profiling and Control Through GSM Network.

4. Ashna K, George SN (2011) GSM Based Automatic Energy Meter Reading System with Instant Billing.

5. Kulkarni B (2013) GSM Based Automatic Meter Reading System Using ARM Controller. IJETAE 2: 446-448.

6. Ashna k (2013) GSM Based Automatic Energy Meter Reading System with Instant Billing. IEEE.

7. Kesav OH, Rahim BA (2012) Automated Wireless Meter Reading System for Monitoring and Controlling Power Consumption. IJRTE 2: 66-69. 